\title{
Impact of demand response on occupants' thermal comfort in a leisure center
}

\author{
Andreea Le Cam (D) Joanna Southernwood • \\ Daniel Ring $\cdot$ Dan Clarke $\cdot$ Rosie Creedon
}

Received: 21 September 2020 / Accepted: 24 May 2021 /Published online: 2 December 2021

(C) The Author(s) 2021

\begin{abstract}
Many assets that are normally installed during an energy-efficient building retrofit can also be used to provide flexible services to the electricity grid. By turning off or turning down some mechanical systems during peak times, it is possible for a building to reduce its load on the electricity network. A field demand response event was simulated at a leisure center in Ireland to evaluate the suitability of the site to participate in the Irish demand response market, to assess how much flexibility it can provide, how much the indoor conditions changed during the test, and to examine whether these remained within satisfactory limits. A survey was conducted to determine whether the occupants perceived any changes to
\end{abstract}

A. Le Cam $(\bowtie) \cdot$ J. Southernwood

International Energy Research Centre, Tyndall National

Institute, University College Cork, Cork, Ireland

e-mail: andreea.lecam@gmail.com

J. Southernwood

e-mail: jo@carbonminded.co.uk

D. Ring

Noel Lawler Green Energy Solutions, Kilkenny, Ireland e-mail: DanielRing@nlce.ie

D. Clarke

Kiwi Power, London, UK

e-mail: dandotclarke@hotmail.com

R. Creedon

Energy Engineering Department, University College Cork, Cork, Ireland

e-mail: rosie.creedon@umail.ucc.ie their thermal comfort. The simulation was achieved by identifying non-critical mechanical equipment and turning them off for $2 \mathrm{~h}$. A processing station for demand response and energy monitoring delivered the demand response signal to the site's building management system. The results show that this site had a flexibility potential of $45 \mathrm{~kW}$, which is considered too low to participate in the demand response market, as Irish aggregators favor sites that can offer over $250-\mathrm{kW}$ flexibility. However, the indoor thermal conditions remained within reasonable ranges and the occupants did not notice the impact of the demand response event. This shows that theoretically, if smaller sites were allowed to sell their flexibility to the electricity market, such leisure centers could participate in demand response services without impacting occupants' comfort.

Keywords Demand response · Flexibility · Indoor air quality $\cdot$ Thermal comfort $\cdot$ Leisure center

\section{Introduction}

The electricity grid is a network of transmission and distribution lines that transport power from where it is generated (such as power stations and renewable energy installations) to where it is used (such as buildings and street lights). To ensure grid stability, electricity supply must match electricity demand at all times. Demand response (DR) is the shifting 
or shedding of demand for electricity during periods with high electricity prices or electrical grid stress in order to balance the supply and demand for electricity. DR can be particularly useful in reducing the dependency of the electricity network on inefficient fossil-fuel plants during periods of peak demand or to reduce stress on the electricity grid during extreme weather conditions (Panfil, 2014). A further benefit of DR is that it can also be used to reduce the problems caused by the intermittent and distributed generation from renewable energy sources by stabilizing both the physical electricity grid and the electricity market.

The US Department of Energy defines demandside management as the "planning, implementation and monitoring of utility activities designed to encourage consumers to modify patterns of electricity usage, including the timing and level of electricity demand" (Leonard, 1998). DR provides an opportunity for consumers to become prosumers (both producers and consumers of energy). They can do this by either exporting energy to the grid or by reducing equipment usage during peak usage periods, in response to time-based rates (such as time of use pricing, critical peak pricing, variable peak pricing, real-time pricing) or other financial incentives set by the electricity network operator. The reduction of the equipment's electrical usage is normally achieved by turning down or turning off non-critical equipment for a specified period of time or even shifting the time of operation to a non-critical period for the electric network. While there are great benefits to demand response, turning down or turning off heating, ventilating, and air conditioning (HVAC) systems for a short period of time generates changes in the indoor temperature, therefore impacting the thermal comfort of occupants. There is a need to study the effect of demand response on the building occupants to better understand its impact on their thermal comfort, health, overall well-being, and productivity (Aghniaey et al., 2019).

This study examined the potential for the provision of demand response services through load shedding in a typical leisure center in Ireland and the impact that this could have on the perceived thermal comfort of the building occupants. The particular leisure center in this study uses a combined heat and power (CHP) unit to provide the majority of its usual heating and electrical requirements and is unable to export excess electrical power to the grid due to the lack of grid synchronization equipment. This means that the real-world opportunities for this site to participate in demand response are limited in this case. Nevertheless, the study gives an indication of the magnitude of the demand response opportunity for a site that does have the ability to export onsite generation capacity to the electricity network, and the load shedding potential for a similar site without any onsite generation equipment.

\section{Occupant thermal comfort}

ASHRAE defines thermal comfort as "the condition of mind that expresses satisfaction with the thermal environment and is assessed by subjective evaluation" (American Society of Heating Refrigerating AirConditioning Engineers, 2017). According to some studies, females are more likely than males to express thermal dissatisfaction with room temperature and tend to notice deviations from the optimal temperature range more acutely than men (Karjalainen, 2007). The difference in thermal needs of females and males has been argued to be attributed to clothing differences (Karjalainen, 2012). The evidence to prove the difference between female and male thermal comfort comes mostly from field studies; however, there is little laboratory evidence to support this, meaning that evidence is anecdotal and perhaps circumstantial. Fanger found that women are more sensitive to fluctuations in thermal levels than men and tend to feel cooler when conditions are cooler, but concluded that for identical clothing and activity, there were few gender differences in warmer conditions (Fanger, 1970). Because women have lower skin temperature and evaporative loss when compared to men, it compensates for the lower overall metabolic rate of women. This led Fanger to deduce that human thermal perception does not vary with gender (Fanger \& Langkilde, 1975). Age, gender, weight, body fat, and thermal history are all factors that have been seen to influence thermal comfort levels in individuals (Lan et al., 2008; Van Hoof, 2008).

Demand response and thermal comfort studies

There have been several studies analyzing the impact of demand response control strategies on the thermal comfort of building occupants. However, most of them employ building simulation tools or 
experiments in climate-controlled chambers rather than field tests in active real-world buildings due to a range of barriers that prevent commercial buildings from being able to offer their flexibility potential to the market. The variation in demand response market maturity throughout Europe currently makes participation impossible in some countries, and the strict pre-qualification conditions and high minimum load requirements set by regulators constitute major barriers to entry to owners and operators of commercial buildings.

A study using the IDA Indoor Climate and Energy simulation tool investigated the impact of demand response on thermal comfort and energy cost in detached residential houses in a cold climate (Alimohammadisagvand et al., 2017). It concluded that the lowest acceptable indoor air and operative temperatures can be reduced to $19.4{ }^{\circ} \mathrm{C}$ and $19.6{ }^{\circ} \mathrm{C}$, respectively. In another investigation, the thermal comfort of 56 participants was examined while direct load control conditions were simulated in a climate chamber. Direct load control is a demand response program in which specific appliances are cycled on and off during peak demand periods. The outcome of the experiment shows that only half of the direct load conditions were acceptable to the participants (Zhang et al., 2016).

An experiment at the University of Georgia questioned 1381 university students in 46 classrooms about their thermal perception during periods when zone temperatures were adjusted (to simulate a building's reaction to a demand response event) (Aghniaey et al., 2018). The results showed that the occupants' perception of thermal comfort improved as the air temperature increased, and the majority of students was satisfied with the indoor air temperature. They concluded that the zone temperatures could be increased from $20{ }^{\circ} \mathrm{C}$ up to $26{ }^{\circ} \mathrm{C}$ without significantly compromising occupant thermal comfort.

A field study on air-conditioned offices in California showed that raising the cooling temperature set point by more than $1.7{ }^{\circ} \mathrm{C}$ resulted in a dissatisfaction rate of more than $20 \%$ (Xu, 2009). A later study conducted on a university campus found that there is potential for temporarily increasing the cooling temperature set points by at least $2{ }^{\circ} \mathrm{C}$ across the campus without impairing occupant thermal comfort (Aghniaey et al., 2019). Another test carried out in Korea in air-conditioned open office spaces showed that the occupants feel comfortable even at $28{ }^{\circ} \mathrm{C}$, which corresponds to an increase in set point temperature of $2{ }^{\circ} \mathrm{C}$ (Zhang et al., 2011).

All of these trials show that thermal comfort is highly subjective, that the climate plays an important role in how people perceive comfort, and that theoretical simulations do not necessarily represent reallife behavior. This article presents a demand response event simulation that was carried out in October 2018 to determine the feasibility of demand response in small- to medium-sized leisure centers, while assessing its impact on the indoor air conditions and the perception of thermal comfort of the occupants. Due to regulatory restrictions, the building could not participate in a real demand response event so equipment was connected to the building management system (BMS) to send signals that would simulate a request from the transmission system operator (TSO). This is the first study that tries to quantify the magnitude of the flexibility available in typical Irish leisure centers to determine if this type of building could be a good candidate for participating in demand response programs.

This investigation was undertaken as part of the NOVICE project, which showed that energy-efficient building renovations often result in smarter buildings that are better able to manage energy consumption. This increased smartness and controllability create opportunities for the building to participate in demand response events. By combining the revenue streams from demand response and energy efficiency measures, the payback period for the investments in the building renovations can be reduced, which strengthens the business case for energy-efficient building renovation and could help to accelerate the market uptake of energy performance contracting in Europe. While it was considered outside the scope of this study to examine the rebound effect (i.e., the idea that after participating in a demand response event the building must use additional energy to recover the conditions to their normal operating range), the concept was explored in another study undertaken by the NOVICE project that modeled the revenue streams and costs of implementing energy efficiency and demand response measures in different building archetypes (Amann et al., 2020). The analysis assumed that revenues obtained from demand response events had to cover the rebound effect. Because the cost associated with the rebound effect is 
considerable, the demand response revenues reduced significantly in certain cases.

\section{General description of the building}

The building that was used for testing is the Ballymun Sports and leisure center (Fig. 1), which is located in the area of Ballymun, North Dublin, Co. Dublin, Ireland. It was built as part of a mixed-use development including apartments, retail, and belowground parking. The construction of the center was completed in 2005 and subsequently underwent a series of energy efficiency upgrades, as part of Ireland's first publicly procured Energy Performance Contract (EPC) in 2017. EPC is a "pay for performance" approach to installing and operating energy technologies on a site, where the cost savings are guaranteed by an Energy Services Company (ESCO) (Sustainable Energy Authority of Ireland, 2020).
The EPC upgraded the BMS and control systems in the building, which allowed better control of a greater range of equipment and made it possible for the site to participate in demand response events.

\section{Building function}

The main function of the building is as a sports and leisure facility, comprising of a swimming pool hall (shown in Fig. 2) with a $25-\mathrm{m}$ pool and an activity pool with slides. There is also a large sports hall containing exercise machines, an adjacent weights room, a spinning room, cardio gyms, an aerobics studio, and a dance studio. Large "wet" changing rooms are provided of the pool hall and "dry" changing rooms are provided for users of all areas except the pool. All user areas are on one floor and a large air-handling plant room is located over the foyer, while a large basement plant room is located below the pool and foyer area.
Fig. 1 Ballymun Sports and leisure center

Fig. 2 Ballymun leisure center pool hall
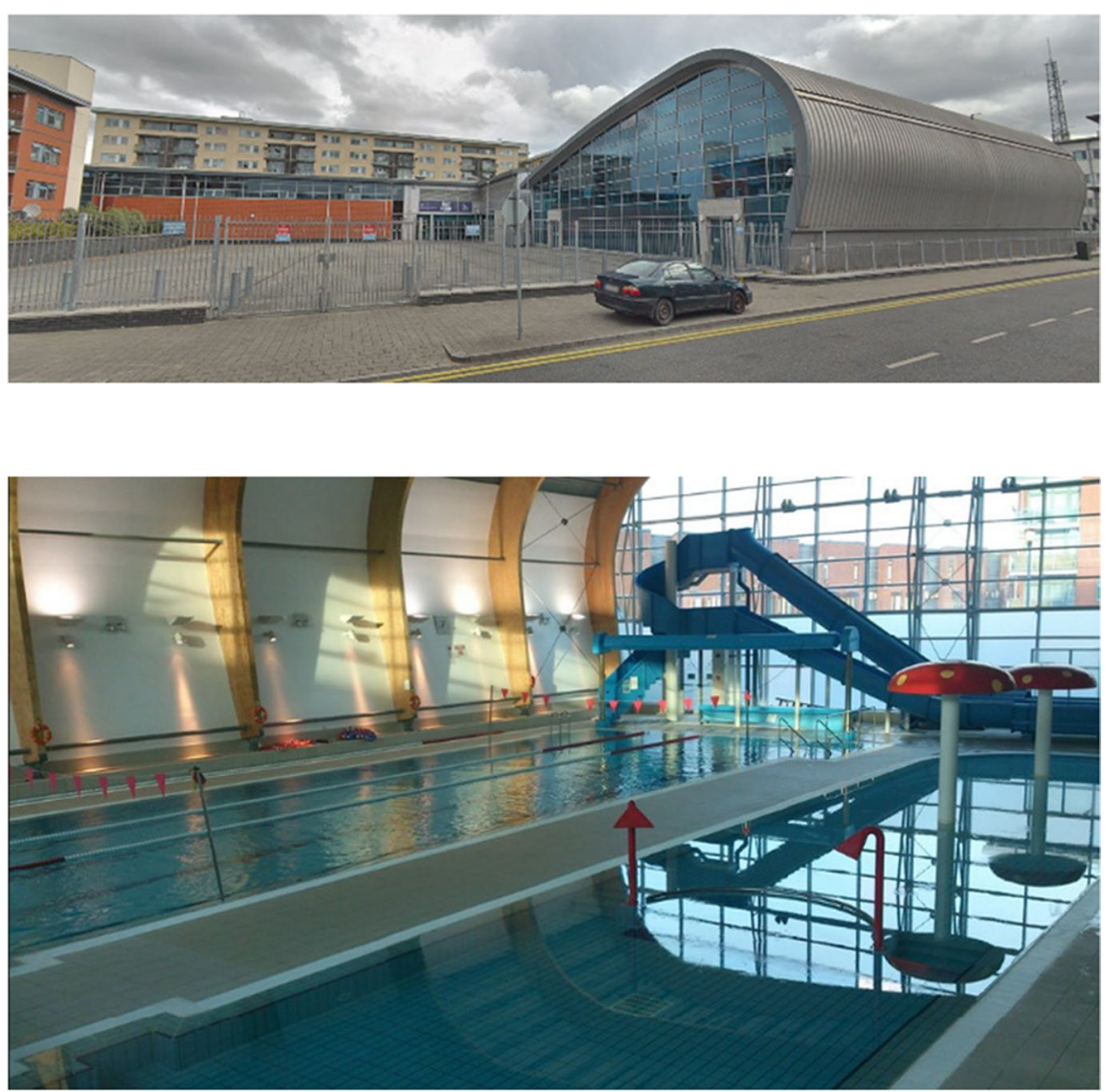
Building construction

The leisure center is an L-shaped construction, facing east/west. The building consists of a double-height pool hall with a curved steel trapezoidal pitched roof system with load-bearing glulam beams and steel cable supports. The walls are made of concrete construction for the foundation and glass façade with aluminum and steel frame with areas of cladding and vents. The building's conditioned spaces are mainly on the ground floor located over a basement car park and the pool plant room.

\section{Occupancy}

The center is operated for $17 \mathrm{~h}$ per day (06:00-23:00), during weekdays, with early closing on Fridays (06:00-21:00) and for $8 \mathrm{~h}$ per day during the weekend (09:00-17:00). There are about 230,000 visitors per year, which is approximately 630 people per day on average.

\section{Electrical equipment}

As part of the EPC, the Ballymun Center upgraded all lighting in the building to energy-efficient LED lighting. There are 10 extraction fans throughout the building with a power rating of $0.25 \mathrm{~kW}$ each, treadmills $(22 \mathrm{~kW})$, a steam room generator $(6 \mathrm{~kW})$, a sauna heater $(6 \mathrm{~kW})$, and several miscellaneous appliances of small power rating.

Heating, ventilating, and air conditioning system

The building's low-pressure hot water (LPHW) is heated via six Victrix Pro 120-kW modular pack of condensing gas boilers which are connected to the LPHW circuit via a $690-\mathrm{kW}$ heat exchanger. A natural gas-fired CHP unit (EGE-06L) of $110 \mathrm{~kW}_{\mathrm{e}} / 185$ $\mathrm{kW}_{\text {th }}$ was installed as part of the EPC contract and provides an additional $186 \mathrm{~kW}_{\text {th }}$ of heat to the LPHW system giving a total heating capacity of $875 \mathrm{~kW}$. It is estimated that the CHP run hours are $4050 \mathrm{~h} / \mathrm{annum}$.

Heat is delivered to most areas of the building via air-handling units (AHUs) which supply heated fresh air and provide humidity control to the main conditioned spaces of the leisure center. Some of the units are fitted with variable speed drives (VSDs) and various forms of heat recovery. The AHUs are controlled by a centralized BMS controller. The damper positions and the air change rates are also controlled via the BMS system to minimize the volume of fresh air that requires heating. Each AHU operates its own set point temperatures to maintain comfort levels within the spaces as per the recommended comfort conditions given in CIBSE guide A (Chartered Institution of Building Services Engineers, 2006).

\section{Energy use}

The leisure center is metered separately from the rest of the multi-use development. During the 2018 calendar year, the site consumed 299,897 kWh of electricity and $1,873,544 \mathrm{kWh}$ of natural gas, giving a total site energy consumption of 2,173,441 kWh/annum.

The CHP unit generates approximately 311,850 $\mathrm{kWh}$ of electricity. No electricity is exported from the site, as the CHP unit does not have the necessary synchronization equipment required for export to the grid. The CHP control strategy is therefore electrically led and all electricity is used on site with the CHP covering the majority of the building's electrical load during normal operation.

Indoor operating conditions

Comfort conditions and set points are maintained as per CIBSE guide A (Environmental Design) recommendations for space function-summer/winter operative temperatures. All temperature set points and setbacks are scheduled in the BMS controller and are given in Table 1. There is also a refrigerationbased cooling unit on the main gym air-handling unit (AHU) with a $16{ }^{\circ} \mathrm{C}$ set point temperature and a permissible comfort range of $15-17^{\circ} \mathrm{C}$.

\section{Demand response event simulation}

Due to the current regulatory framework and tariff structures in Ireland, the site could not participate in a real demand-side response event triggered by the transmission system operator (TSO). The flexibility potential of the site was considered too low to be of interest to the TSO and the potential revenues were too small to be of interest to Irish demand response aggregators. Therefore, in order to artificially "trigger" a demand response event 
Table 1 Heating set point temperatures

\begin{tabular}{llc}
\hline Zone & Temperature $\left({ }^{\circ} \mathrm{C}\right)$ & \\
\cline { 2 - 3 } & Set point/setback & $\begin{array}{c}\text { Permissible } \\
\text { comfort range }\end{array}$ \\
\hline Pool water temperature & 29 & $28.5-29.5$ \\
Pool hall & 30 & $29-31$ \\
Sauna & $80 / 90$ & $79-91$ \\
Steam room & $47 / 50$ & $46-51$ \\
Main gym & $16 / 18$ & $15-19$ \\
Aerobic studio & $16 / 18$ & $15-19$ \\
Foyer/reception & $18 / 22$ & $17-23$ \\
Changing rooms & $18 / 22$ & $17-23$ \\
Communal areas & $18 / 22$ & $17-23$ \\
Staff rooms & $18 / 22$ & $17-23$ \\
\hline
\end{tabular}

at the desired time, a processing station was connected to the site's BMS which simulated a dispatch signal from the TSO. At the start of the simulated demand response event, the processing station sent signals to the BMS to change set points and other controllable operating parameters in a way that resulted in relevant equipment being turned down or turned off.

The simulated DR event was limited to load shedding and demand reduction and did not include any form of frequency response. Although larger revenues are available for the provision of services like fast frequency response, the site scale and asset profile did not allow access to these schemes. This may have been different if the demand response had been considered as part of the original EPC, as a detailed analysis of the opportunity for fast frequency response might have justified battery storage investment. Export of excess CHP capacity to the grid was also not considered, as the site does not have a maximum export capacity (MEC), which allows a behind the meter generation asset to be paid to export electricity to the grid when required. Currently, in this jurisdiction (Ireland), it is not financially or operationally viable to be awarded a MEC from the distribution system operator (DSO).

\section{Methodology}

The demand response event was simulated at the Ballymun leisure center by turning down or turning off non-essential equipment for $2 \mathrm{~h}$ on Wednesday 3
October 2018 from 17.00 to 19.00. This particular time was selected because weekday evenings are normally the busiest periods for the leisure center; therefore, it represented the worst-case scenario for turning off HVAC equipment.

The CHP normally provides most of the baseload electricity for this building so to measure the turn down potential of a hypothetical leisure center similar to this one, the CHP was turned off via the BMS before the demand response event started. This forced the site to draw all of its electrical load from the electricity grid, allowing the total site electricity consumption to be measured more easily at the point where the main electricity supply entered the building. The building's BMS system automatically records total electricity consumption every $15 \mathrm{~min}$. As this time interval is considered too large to register, the finer details in power change due to the DR event; a data logger was installed at the main electrical incomer to record the electrical power consumption at 1-min intervals.

After turning off the CHP, the demand response event was started by using the processing station to send a signal to the BMS to force the following nonessential equipment to turn off or turn down: (i) all air-handling units, (ii) all extraction fans, except for the toilets, (iii) all low-pressure heating water pumps, excluding domestic hot water (DHW), and (iv) some non-essential water pumps. After $2 \mathrm{~h}$, which is considered the maximum likely duration of a load shedding event in Ireland, the communication equipment sent a further signal to the BMS to return all settings to their normal operating parameters, signaling the end of the simulated DR event. The CHP was also turned on and the building was allowed to return to its normal operating conditions.

The temperature, relative humidity, and $\mathrm{CO}_{2}$ levels were monitored using a handheld meter prior to, during, and at the end of the simulation to check that they remained within acceptable levels throughout the DR event. These measurements were recorded for the three most densely occupied spaces; the pool, the gym, and the reception area. For these spaces, the data logger was placed in the same areas for each repeated measurement to ensure consistency in the measurements. These results were then analyzed to assess whether the values remained within the acceptable comfort range. The pool's water quality monitoring equipment 
continued to operate throughout the event, to ensure that the quality of the pool water did not deviate from normal operating parameters.

Occupants of the leisure centers were surveyed to determine whether they noticed any change in conditions inside the leisure center during the simulated DR event and therefore, whether participating in such an event could affect their thermal comfort levels. Their perception of the temperature, humidity, and air quality was evaluated using a range of questions where participants were asked to rate their level of satisfaction for each parameter. These related to the reception area (where the survey took place) and any other areas of the leisure center where they spent the most time during their visit, on the day in question. The questions were carried out by one surveyor using an iPad. The respondents to the survey before the demand response event are considered as the control group, compared with respondents during the event. The control group serves as a benchmark to measure the results of the experiment and helps to rule out alternative explanations of the experimental results. The participants were not told that a demand response event was taking place, to avoid influencing their answers. The final question of the survey asked if they noticed a change in conditions during their time in the building. This question was deliberately asked at the end of the survey, to avoid leading people towards thinking about changing conditions and potentially influencing their answers on thermal comfort.

Equipment for the demand response event

For the simulation, a processing station for demand response and energy monitoring was installed. It consisted of a control panel and a set of rope current transformers. The control panel delivered the demand response signal to the site's BMS systems that triggered the DR simulation test. It also recorded the load $(\mathrm{kW})$ of the site prior, during, and at the end of the simulation event. The temperature, relative humidity, and $\mathrm{CO}_{2}$ monitoring were conducted by handheld devices, on the day of the trial. The survey with building occupants was carried out by one surveyor, interviewing building occupants, and recording their answers using an iPad.

\section{Results of the demand response simulation}

Available power

The electrical flexibility available through the turn down of equipment at the Ballymun leisure center is approximately $45 \mathrm{~kW}$. Figure 3 shows the power consumption of the Ballymun leisure center before, during, and after the demand response event. The peak, at approximately 16.30, has a maximum value of $85 \mathrm{~kW}$ and shows the impact of the CHP unit turning off and the electrical power consumption of the site switching to the electricity grid. It can be seen that when the demand response event begins at around 17.00 , the consumption initially drops to $30 \mathrm{~kW}$. The smaller peaks and troughs during the event (between 17.00 and 19.00) show the essential equipment turning on and off to maintain safe operating conditions. The power consumption in this time period fluctuates between 30 and $40 \mathrm{~kW}$. The flexibility potential available to the grid through load shedding is therefore approximately $45 \mathrm{~kW}$ and is represented by the difference between the maximum power consumption
Fig. 3 Power at Ballymun leisure center before, during, and after the demand response test

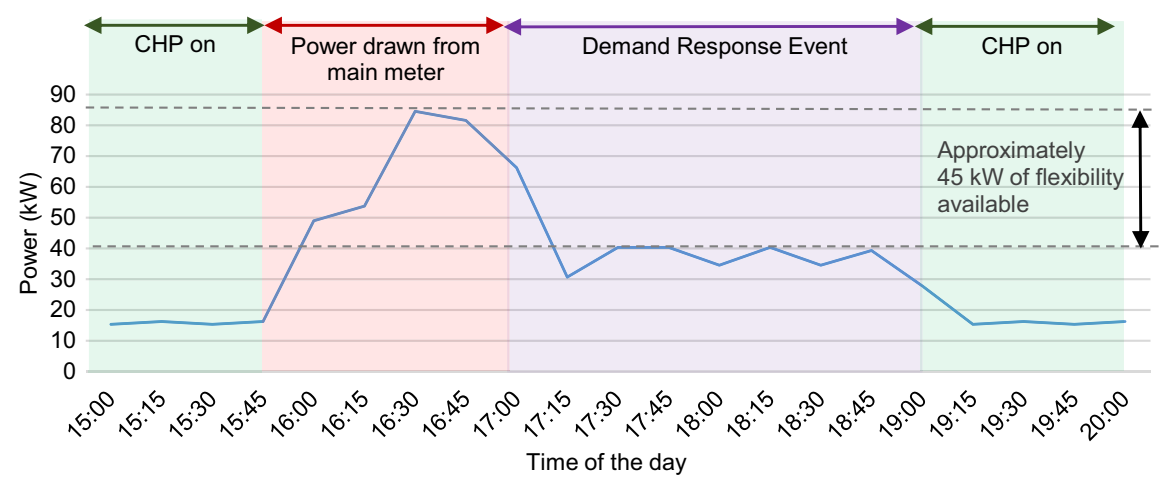


before the DR event and maximum power consumption during the test. The significant drop in power consumption following the end of the demand response event (at 19.00) shows the CHP coming online again, to return the building to normal operating conditions.

At the time of the test, in Ireland, aggregators usually only consider sites with available flexibility of more than $250 \mathrm{~kW}$, for participating in the demand response market. This shows that this site, and possibly other leisure centers, is not yet suitable for selling their flexibility to the grid under today's demand response regulations. If the correct synchronization equipment had been installed with the CHP at the time of the EPC, then the flexibility potential would be higher. By ramping down the site demand to $40 \mathrm{~kW}$ as shown by the simulation, while ramping up the CHP to the maximum electrical load of $110 \mathrm{~kW}$, this would allow the building to export approximately $70 \mathrm{~kW}$. This assumes there is enough thermal capacity to store all the excess heat without dumping heat. To achieve this, the BMS could reduce the boiler output, for example, to allow the excess heat of $185 \mathrm{~kW}_{\text {th }}$ from the CHP to be used to heat the pool water.

Indoor air conditions

\section{1) Indoor air temperature}

Table 2 shows the variation in indoor air temperature of three spaces in the Ballymun leisure center at the beginning, during, and at the end of the simulated DR event. It can be seen that there is a change of approximately one degree Celsius in all spaces and that they stayed within the permissible ranges described in Table 1. It is unclear why there is a slight

Table 2 Indoor air temperature before, during, and after the demand response test

\begin{tabular}{llll}
\hline Zone & \multicolumn{3}{l}{ Indoor air temperature $\left({ }^{\circ} \mathrm{C}\right)$} \\
\cline { 2 - 4 } & $\begin{array}{l}\text { Beginning of DR, } \\
\text { 17:00 PM }\end{array}$ & $\begin{array}{l}\text { During DR, } \\
\text { 18:00 PM }\end{array}$ & $\begin{array}{l}\text { End of } \\
\text { DR, 19:00 } \\
\text { PM }\end{array}$ \\
\hline Pool & 23.4 & 22.3 & 22.1 \\
Gym & 18.6 & 18.9 & 18.3 \\
Reception & 18.7 & 19.8 & 19.3 \\
\hline
\end{tabular}

increase in the temperature recorded in the reception areas, but some differences in indoor air conditions related to the execution of the survey may have contributed to this change. Firstly, our team member conducting the experiment used a portable data logger and had to travel through the different zones (pool, gym, and reception area) at three different times: the beginning, the middle, and the end of the DR event. There is a direct access from the reception area to the pool, which means that the door was opened at least 6 times by our team member, thus letting some warmer air escape from the pool area into the colder reception area. Another change in occupants' behavior caused by the survey is that instead of people passing through the reception area quickly on their way out of the building, they were asked to stop for a few minutes, to answer the survey questions. This could have caused an increase in people density in the area and led to people remaining in this zone for longer than normal. The additional heat, from the increased occupancy of this space, could have led to an increase in the reception air temperature during the DR event.

\section{2) Relative humidity}

Table 3 presents the relative humidity levels at the Ballymun leisure center before, during, and at the end of the demand response event. The relative humidity increased from 70 to $99.1 \%$ in the pool area, but since the occupants are wet from entering the pool, it is likely they will not perceive this difference. The relative humidity levels in the gym area increased considerably ( $16 \%$ change), while the reception area saw only a $1 \%$ increase. It is therefore recommended to monitor the relative humidity levels closely during a demand response event, to

Table 3 Relative humidity before, during, and at the end of the demand response test

\begin{tabular}{llll}
\hline Zone & \multicolumn{2}{l}{ Relative humidity (\%) } \\
\cline { 2 - 4 } & $\begin{array}{l}\text { Beginning of DR, During DR, } \\
\text { 17:00 PM }\end{array}$ & $\begin{array}{l}\text { End of } \\
\text { 18:00 PM } \\
\end{array}$ & $\begin{array}{l}\text { DR, 19:00 } \\
\text { PM }\end{array}$ \\
\hline Pool & 70 & 75.7 & 99.1 \\
Gym & 64.1 & 68.7 & 74.7 \\
Reception & 66.4 & 64.5 & 67.1 \\
\hline
\end{tabular}


ensure that they remain within the acceptable comfort range.

3) $\mathrm{CO}_{2}$ levels

Carbon dioxide is a normal constituent of the atmosphere. Table 4 shows the acceptable $\mathrm{CO}_{2}$ values given by the European standard EN 13,779, which classifies the indoor air quality in four categories, from IDA 1 - high air quality buildingsto IDA4-low air quality buildings. ASHRAE recommends $\mathrm{CO}_{2}$ levels not exceeding $700 \mathrm{ppm}$ above outdoor levels (American Society of Heating Refrigerating Air-Conditioning Engineers, 2007).

Recent recommendations show that any levels above 1,000 ppm could cause potential health problems for occupants depending on the duration of exposure (Fig. 4).

Some of these health problems range from drowsiness, headaches, nausea, to more serious health problems such as toxicity or oxygen deprivation and in even higher concentration, death could be a direct effect of $\mathrm{CO}_{2}$ levels (Table 5).

There have been many studies that have analyzed the direct risks of increased indoor $\mathrm{CO}_{2}$ concentrations for human health based on frequency and duration of exposure. Jacobson et al. (2019) have carried a literature review (Fig. 5) and concluded that there is evidence that exposure even to levels as low as $1000 \mathrm{ppm}$ could cause potential health risks.

It is therefore necessary to introduce outside fresh air to the building in order to dilute contaminants and odors in the indoor space. The volume of fresh air required depends on the occupancy rates and activities of occupants, while at the same time balancing energy conservation requirements.

Table 4 Acceptable $\mathrm{CO}_{2}$ values for indoor air quality

\begin{tabular}{lll}
\hline Category & Quality & $\begin{array}{l}\mathrm{CO}_{2} \text { above } \\
\text { outdoor air } \\
(\mathrm{ppm})\end{array}$ \\
\hline IDA 1 & High & $\leq 400$ \\
IDA 2 & Medium & $400-600$ \\
IDA 3 & Moderate & $600-1000$ \\
IDA 4 & Low & $\geq 1000$ \\
\hline
\end{tabular}

Values were taken from European Standard EN 13,779

\section{Carbon Dioxide $\left(\mathrm{CO}_{2}\right)$ Hazard Scale}

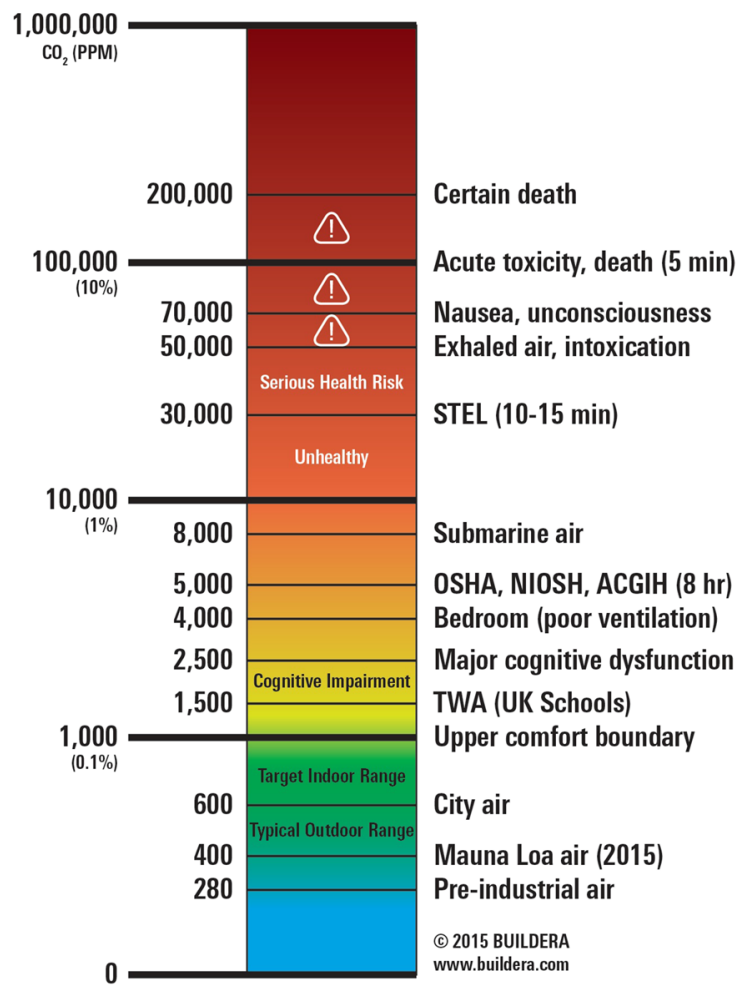

Fig. $4 \mathrm{CO}_{2}$ concentration levels versus occupants' health problems ( source www.buildera.com)

Table $5 \mathrm{CO}_{2}$ levels and potential health problems

\begin{tabular}{ll}
\hline $\mathrm{CO}_{2}$ levels (ppm) & Potential health problems \\
\hline $250-400$ & Background (normal) outdoor air level \\
$400-1000$ & Good air exchange \\
$1000-2000$ & Complaints about drowsiness and poor air \\
$2000-5000$ & $\begin{array}{l}\text { Headaches, sleepiness, and stagnant, stale, } \\
\text { stuffy air. Poor concentration, loss of } \\
\text { attention, increased heart rate, and slight } \\
\text { nausea may also be present } \\
\text { Other gases could also be present. Toxicity } \\
\text { or oxygen deprivation could occur. This } \\
\text { is the permissible exposure limit for daily } \\
\text { workplace exposures } \\
\text { Immediately harmful due to oxygen dep- } \\
\text { rivation }\end{array}$ \\
40,000 &
\end{tabular}

Values were taken from the Wisconsin Department of Health Services website (last revised on December 20, 2019) 


\begin{tabular}{|c|c|c|c|}
\hline & $\mathrm{CO}_{2}$ concentration $(\mathrm{ppm})$ & Duration & Selected key references \\
\hline \multicolumn{4}{|c|}{ Adverse health outcomes associated with acute $\mathrm{CO}_{2}$ exposure } \\
\hline $\mathrm{CO}_{2}$ retention & $1,000-5,000$ & $<4 h$ & $\begin{array}{l}\text { Zhang et al. }{ }^{75} \text {; Zhang et al. }{ }^{73} \text {; Vehvilainen } \\
\text { et al. }{ }^{77} \text {; Shiraram et al. }{ }^{76}\end{array}$ \\
\hline Inflammation & $2,000-4,000$ & $2 \mathrm{~h}$ & Thom et al. ${ }^{80,87}$; Schneberger et al. ${ }^{82}$ \\
\hline Cognitive effects & $1,000-2,700$ & $1-6 h$ & $\begin{array}{l}\text { Kajtar and Herczeg }{ }^{85} ; \text { Satish et al. }{ }^{86} ; \text { Allen } \\
\text { et al. } .^{87,88} ; \text { Zhang et al. }{ }^{75} ; \text { Zhang et al. }{ }^{73,74} \text {; } \\
\text { Rodeheffer et al. }{ }^{91} ; \text { Snow et al. } .^{90}\end{array}$ \\
\hline \multicolumn{4}{|c|}{ Adverse health outcomes associated with chronic $\mathrm{CO}_{2}$ exposure } \\
\hline Chronic, low-grade systemic inflammation & $\sim 3,000$ & $13 d$ & Zappulla ${ }^{2,69} ;$ Beheshti et al..$^{101}$ \\
\hline Bone demineralization and kidney calcification & $\sim 2,000-3,000$ & $60-90 d$ & Schaefer et al. ${ }^{102,103}$ \\
\hline $\begin{array}{l}\text { Chronic, low-grade (sub-clinical) respiratory } \\
\text { acidosis }\end{array}$ & Unknown & Decades & Carnauba et al. ${ }^{109} ;$ Robertson ${ }^{61,106}$ \\
\hline Behavioural changes and physiological stress & $700-3,000$ & $13-15 d$ & $\begin{array}{l}\text { Beheshti et al. }{ }^{101} ; \text { Wade et al. }{ }^{104} \text {; Martrette } \\
\text { et al. }{ }^{111} \text {; Kiray et al. }{ }^{112}\end{array}$ \\
\hline Hedonic feeding behaviours & Unknown & Ecological & Hersoug et al.113; Zheutlin et al.1 \\
\hline Oxidative stress and endothelial dysfunction & $3,000-5,000$ & $13 \mathrm{~d}$ to 6 months & Beheshti et al. ${ }^{101}$; Thom et al. ${ }^{80,81}$; Zwart et al. ${ }^{119}$ \\
\hline
\end{tabular}

Fig. 5 Overview of potential health effects from Jacobson's literature review

Table 6 presents the $\mathrm{CO}_{2}$ levels at the Ballymun leisure center, measured with the handheld portable data logger. The leisure center remained within a reasonable range of $\mathrm{CO}_{2}$ levels during the demand response event, even though the non-essential HVAC systems were turned off. While the reception and the pool area saw small increases in $\mathrm{CO}_{2}$ levels (of 5\% and 11\%, respectively), the change in the gym area is significant $(81 \%)$ and the indoor air quality changed from medium to low levels. An exposure of $2 \mathrm{~h}$ to levels higher than $1000 \mathrm{ppm}$ is unlikely to cause health problems, but ideally, the indoor air levels should be kept under $1000 \mathrm{ppm}$, to minimize complaints from occupants. It is therefore recommended that $\mathrm{CO}_{2}$ levels should also be closely monitored in the case of a demand response event.

Table $6 \mathrm{CO}_{2}$ levels before, during, and at the end of the demand response test

\begin{tabular}{llll}
\hline Zone & \multicolumn{3}{l}{$\mathrm{CO}_{2}$ levels (ppm) } \\
\cline { 2 - 4 } & $\begin{array}{l}\text { Beginning of DR, } \\
\text { 17:00 PM }\end{array}$ & $\begin{array}{l}\text { During DR, } \\
\text { 18:00 PM }\end{array}$ & $\begin{array}{l}\text { End of } \\
\text { DR, 19:00 } \\
\text { PM }\end{array}$ \\
\hline Pool & 745 & 745 & 784 \\
Gym & 593 & 942 & 1073 \\
Reception & 530 & 562 & 590 \\
\hline
\end{tabular}

\section{Thermal comfort}

The occupants of the leisure center were surveyed in the reception area before and during the simulated demand response event. The questions asked were carefully chosen to ensure they were not leading the participants in any way. To remove any bias, the respondents were told that the purpose of the survey was to check their level of thermal comfort to ensure more enjoyable visits in future and did not specifically refer to any demand response event. The participants were asked to first comment on their comfort in terms of temperature, humidity, and air quality in the areas of the leisure center in which they had spent time (Fig. 6).

The most relevant question, regarding whether they noticed a change in conditions during their time in the building, was placed at the end of the survey. The reason for this was to ensure the respondents did not realize that this was the key question and to prevent them from answering differently because of its importance.

The respondents indicated their thermal satisfaction in the reception area (where the survey took place) and in any other area of the building where they had spent the previous $20 \mathrm{~min}$. This is therefore counted as two votes per person, one for each area the user of the leisure center facilities had occupied. Satisfaction in the leisure center is only 
1.) What is your gender? (we are asking this question because part of our research involves examining whether gender plays a role in thermal comfort levels) Male/ Female/ Other/ Prefer not to say

2.) What was your main activity in the last 20 minutes? (we ask this question because your activity level affects how warm or cold you feel) Sitting/Walking/ Running/ Swimming/ Intense exercise (e.g. badminton, squash, football etc)/ Gentle exercise (e.g. yoga)/ Changing/Showering

3.) Please indicate which items of clothing from the list below you are currently wearing (select all that apply: what you are wearing can impact on how warm or cold you feel so we ask this question to account for this.) Top with no sleeves/ Top with short sleeves/ Top with long sleeves/ Knee length or above skirt/trousers/Below the knee skirt/trousers/ Leggings/ Tights or other hosiery/ Socks/ Coat (winter)/ Jacket (light)/ Hat/ Scarf

4.) How would you rate the temperature in the area we are in now? $\begin{array}{llllllllll}\text { Too cold } & 1 & 2 & 3 & 4 & 5 & 6 & 7 & \text { Too hot }\end{array}$

5.) How would you rate the humidity levels in the area we are in now? $\begin{array}{lllllll}\text { Too humid } & 1 & 2 & 3 & 4 & 5 & \text { Just right }\end{array}$

6.) How would you rate air quality in the area we are in now? $\begin{array}{llllllll}\text { Too stuffy } & 1 & 2 & 3 & 4 & 5 & \text { Just right }\end{array}$

7.) In which other area of the leisure centre did you spend most time today? Pool/ Changing rooms/ Sports hall/ Reception/ Cafe

8.) Thinking about that area and the time you spend there, how would you rate the temperature in that area? $\begin{array}{lllllllll}\text { Too cold } & 1 & 2 & 3 & 4 & 5 & 6 & 7 & \text { Too hot }\end{array}$

9.) How would you rate the humidity levels in that area at the time you were there? $\begin{array}{lllllll}\text { Too humid } & 1 & 2 & 3 & 4 & 5 & \text { Just right }\end{array}$

10.) How would you rate air quality in that area at the time you were there? $\begin{array}{lllllll}\text { Too stuffy } & 1 & 2 & 3 & 4 & 5 & \text { Just right }\end{array}$

11.) Did you notice any change in conditions during the time you were there? Yes, it became hotter/Yes, it became colder/Yes, it became more humid/Yes, it became less humid/Yes, it became stuffier/Yes, it became less stuffy/ No, did not notice any change

Fig. 6 Survey questions asked to the occupants of the leisure center

relevant to the experiment if it differs during the demand response event, compared to during normal operating conditions.

Figure 7 shows the proportion of survey respondents that noticed a change in conditions during their visit. The vast majority of the building users stated that they did not notice the change in conditions during the simulated demand response event (in gray). A "correct" change is a change that was noticed by the respondents during the event and is also supported by the measurements of the temperature, relative humidity, and $\mathrm{CO}_{2}$ levels in the leisure center at those times. A change that was noticed outside of this time, before (in the control group), or after is considered "incorrect," as it was not caused by the simulated demand response event conditions.

The survey indicates that $76.5 \%$ of respondents did not perceive a change in thermal comfort, while $11.8 \%$ of interviewed occupants noticed the same change in conditions that is supported by the metered results. A further $11.8 \%$ of the respondents stated that they noticed a change in conditions that occurred outside of the test period; therefore, these changes do not relate to the demand response simulation.

\section{Changes noticed}

The breakdown of the results is shown in Fig. 8. One correct response was that it became colder in the pool area, near the middle of the event; this is substantiated by the measured data. The air in the pool hall became $0.7{ }^{\circ} \mathrm{C}$ to $1.1{ }^{\circ} \mathrm{C}$ colder during the event. The exact time that this change occurred cannot be determined with hourly recordings. The faster a change occurs, the more likely an occupant is to notice the said change. The second correct response was that it became more humid in the reception area. This is also considered a correctly identified change, as this building occupant answered the survey at the end of the DR event, when measurements show that relative 
Fig. 7 Ballymun leisure center survey results on thermal comfort

\section{Ballymum occupants results}

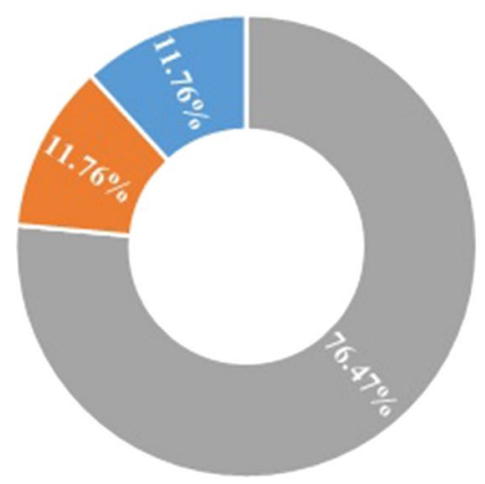

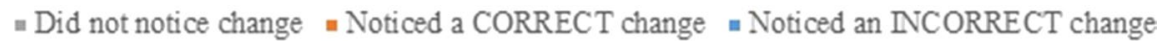

humidity in the reception area had indeed increased. Even though this answer came at the end of the DR event, the occupant had been present on site for the whole test; therefore, his answer is considered as being part of the DR event period.

Nine people answered the questions before the test, and eight people answered during the test. Since the people were interviewed while leaving the gym, the number of respondents was limited due to the short period of $2 \mathrm{~h}$ of the DR event. Due to the low numbers of participants, it is difficult to accurately or certainly say that there was no change in comfort levels. However, the results compiled show little to no dissatisfaction in the leisure center and indicate that this type of turn down demand response event could be implemented in leisure centers, with little to no impact on thermal comfort, given the right conditions. Further experiments would be needed to verify this result, ideally repeating the test on a very cold day in winter and a very warm day in summer, to check if these results have any weather dependency.

General satisfaction results

Figure 9 shows the overall satisfaction results in terms of air temperature, relative humidity, and air quality. Overall temperature satisfaction throughout the test was acceptable. There appears to be a significant change in how people perceive the thermal levels in the leisure center throughout the experiment. Before the test, the overall temperature satisfaction follows a bell curve, with $44 \%$ of respondents indicating that the temperature was "Just Right." During the test, the majority of respondents $(81 \%)$ was completely satisfied with the indoor temperature.

Humidity satisfaction varied; however, the overall majority of respondents (69\%) indicated that the humidity was just right or only slightly too humid
Fig. 8 Breakdown of survey results at Ballymun Center

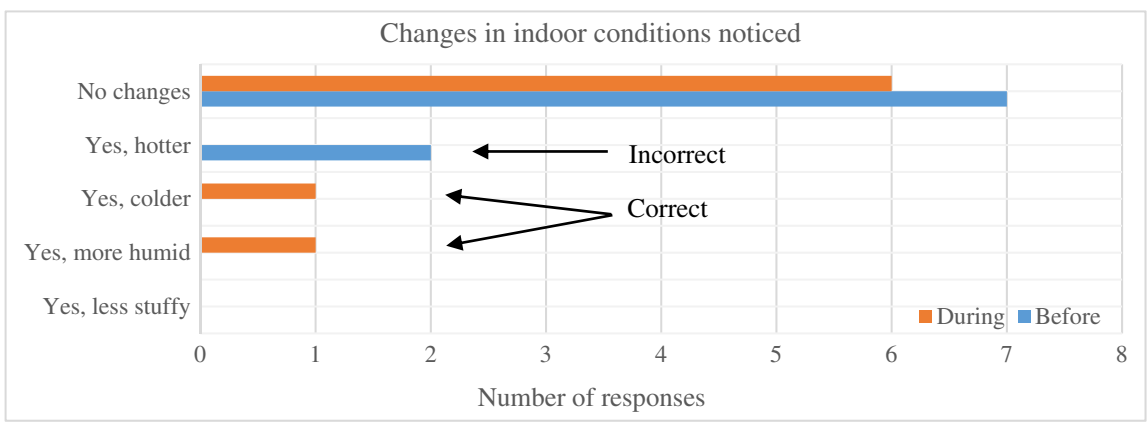


Fig. 9 Overall satisfaction rate before and after the DR test

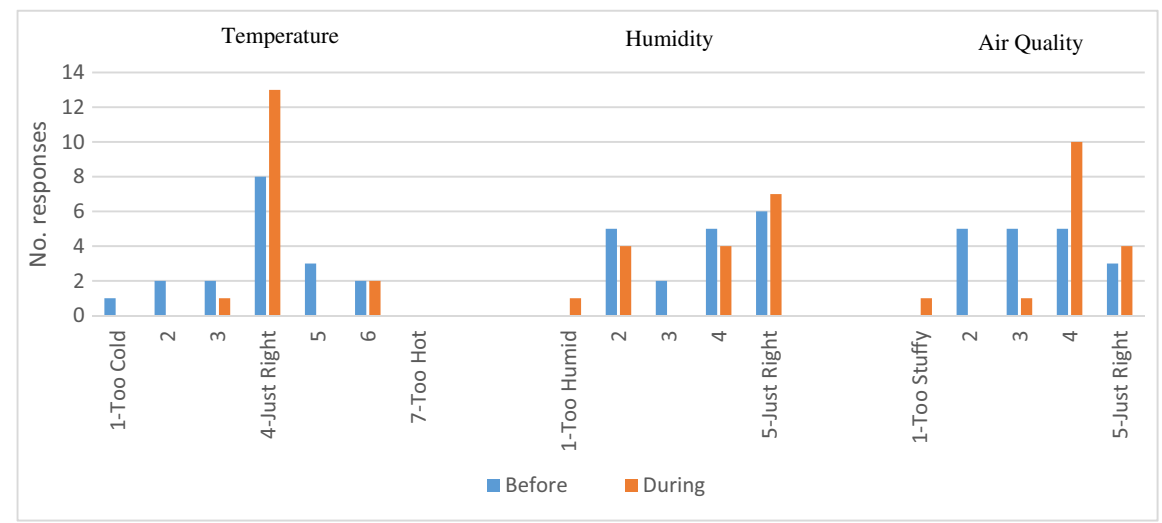

("4" and "Just Right"). The responses did not differ in trends before and during the demand response event. Approximately the same number of people responded to each category in both time periods. However, the most extreme negative response occurred during the event. It is to be expected that the humidity in a pool area is greater than ideal indoor levels. Therefore, a lack of complete satisfaction with the humidity levels is acceptable.

Air quality satisfaction increased during the demand response event, compared to before. Before the test, the air quality in the leisure center was the same as normal operation, showing that the control group indicated a varied response to the air quality. The portion of the respondents that indicated the air quality was acceptable ("4" and "Just Right") before the demand response event was just $44 \%$, compared to the period during the simulation where that percentage went up to $88 \%$.

Factors that influence the results

Some of the potential factors that could influence the perception of the thermal comfort of survey participants, while at the leisure center, were recorded during the survey. The type of exercise each respondent had performed immediately before the survey and the type of clothing they wore was documented. In general, those who had been engaged in walking, gentle exercise, or intense exercise show the highest portion of satisfactory response with the indoor air temperature and humidity levels. Swimmers generally had a poor perception of the air quality, as there were equal numbers of positive and negative responses. The number of layers of clothing worn by an occupant could affect their perception of the temperature and other indoor conditions. The analysis of the clothing items the occupants were wearing shows that they were dressed appropriately, considering the weather and type of exercise they were performing. Those performing intense exercise all wore a top with short sleeves and no jacket, while the majority of those performing less intense activities wore tops with long sleeves and sometimes had a light jacket on as well.

The weather in October of 2018 was highly erratic with the highest temperature of $19{ }^{\circ} \mathrm{C}$, the lowest temperature of $-4{ }^{\circ} \mathrm{C}$, and the humidity ranging from 43 to $100 \%$ in the month. However, the outdoor conditions did not vary greatly during the 2-h period of the test. The air temperature was $16{ }^{\circ} \mathrm{C}$ at $17: 00$ and $14{ }^{\circ} \mathrm{C}$ at 19:00, the outdoor RH changed from 77 to $88 \%$ from 17:00 to $19: 00$, and the sky was predominantly cloudy on the day of the test. The two degrees Celsius decrease in outdoor air temperature does not seem to have been felt by the occupants, even though the equipment was turned off for $2 \mathrm{~h}$. This indicates that the building fabric was able to maintain comfortable indoor conditions during the demand response event.

From the previously mentioned studies on thermal comfort, it can be seen that gender may impact the participant's response to the survey. More than half of the participants were male (61\%). This could mean the results are not taking female sensitivity of temperature into account sufficiently for concrete results. In order to have unbiased results, in any future re-run of the trial, more effort should be made to ensure a balanced gender distribution from leisure center users.

The impact of age and body weight on the results was not considered in this study. 


\section{Conclusion}

A demand response event was simulated in October 2018 in a leisure center in Dublin with two objectives: (i) to determine the amount of flexibility available in small to medium-sized leisure centers through load shedding and (ii) to evaluate the impact on the indoor air conditions and the perception of thermal comfort of the occupants.

The study found that small- to medium-sized leisure centers could potentially have available flexibility of $45 \mathrm{~kW}$ through load shedding, which is considered too small to be able to participate in the demand response market under current regulations in Ireland. An aggregation of similar centers or larger leisure centers might be more suitable to participating in demand response events than smaller setups, but this is not enough to be attractive to grid operators and demand response aggregators at this time. For a site with a small turn down capacity, installing a CHP with thermal and electrical storage as part of an energy efficiency project may allow access to the capacity and frequency response markets if market conditions allowed and thus bring the site into the scope of aggregators. For a small- to medium-sized leisure center, a CHP unit could allow the building to export approximately $70 \mathrm{~kW}$ of electrical power, which would increase the flexibility potential of the site by $55 \%$.

The demand response event was simulated through determining the non-critical equipment in the leisure center, and turning it off or down for $2 \mathrm{~h}$, to replicate a typical demand response event. In conclusion, the vast majority of occupants in the leisure center did not notice that a demand response event occurred, causing small changes to the conditions inside the space. The temperature in all monitored areas remained relatively consistent, deviating by approximately $1{ }^{\circ} \mathrm{C}$ in most cases. However, humidity and $\mathrm{CO}_{2}$ levels changed more significantly, indicating that these would need to be monitored closely during any participation in a real demand response event, to ensure that comfortable levels are maintained at all times.

To take advantage of its full demand response market potential, it is recommended that smaller sites should be allowed to participate in flexibility programs. Future work could look into simulating the demand response event in different months of the year, to assess if the impact on occupants' thermal comfort changes with respect to outdoor air conditions.

Acknowledgements Assistance provided by Dublin City Council who allowed the experiment to take place in one of their leisure facilities was greatly appreciated.

Funding Open Access funding provided by the IReL Consortium This work is part of the NOVICE project that has received funding from the European Union's Horizon 2020 research and innovation program under grant agreement No 745594.

\section{Declarations}

Conflict of interest The authors declare no competing interests.

Open Access This article is licensed under a Creative Commons Attribution 4.0 International License, which permits use, sharing, adaptation, distribution and reproduction in any medium or format, as long as you give appropriate credit to the original author(s) and the source, provide a link to the Creative Commons licence, and indicate if changes were made. The images or other third party material in this article are included in the article's Creative Commons licence, unless indicated otherwise in a credit line to the material. If material is not included in the article's Creative Commons licence and your intended use is not permitted by statutory regulation or exceeds the permitted use, you will need to obtain permission directly from the copyright holder. To view a copy of this licence, visit http://creativecommons.org/licenses/by/4.0/.

\section{References}

Aghniaey, S., Lawrence, T. M., Mohammadpour, J., Song, W., Watson, R. T., \& Boudreau, M. C. (2018). Optimizing thermal comfort considerations with electrical demand response program implementation. Building Services Engineering Research and Technology, 39(2), 219-231.

Aghniaey, S., Lawrence, T. M., Sharpton, T. N., Douglass, S. P., Oliver, T., \& Sutter, M. (2019). Thermal comfort evaluation in campus classrooms during room temperature adjustment corresponding to demand response. Building and Environment, 148, 488-497.

Alimohammadisagvand, B., Alam, S., Ali, M., Degefa, M., Jokisalo, J., \& Sirén, K. (2017). Influence of energy demand response actions on thermal comfort and energy cost in electrically heated residential houses. Indoor and Built Environment, 26(3), 298-316.

Amann, C., Southernwood, J., Galdiz, J. I. T. (2020). "D 5.3 Description of scenarios and simulation results and D5.4 Report on revenue flows and feasibility studies", NOVICE project, http://novice-project.eu/D5_3_D5_4_Scenarios_ Revenue_Streams.pdf, retrieved on 15/01/2021 
American Society of Heating Refrigerating Air-Conditioning Engineers (2007). 62.1. (2007). Ventilation for acceptable indoor air quality. American Society of Heating.

American Society of Heating Refrigerating Air-Conditioning Engineers (2017). Thermal environmental conditions for human occupancy: ANSI/ASHRAE Standard 55-2017, ASHRAE

Chartered Institution of Building Services Engineers (2006). Guide A: Environmental design, CIBSE London

Fanger, P. O. (1970). Book Thermal comfort. Analysis and applications in environmental engineering. Pulished by Danish Technical Press, Copenhagen.

Fanger, P. O., Langkilde, G. (1975). "Interindividual differences in ambient temperatures preferred by seated persons.” A.S.H.R.A.E. Transactions 81(2), 140-147.

Jacobson, T. A., Kler, J. S., Hernke, M. T., Braun, R. K., Meyer, K. C., \& Funk, W. E. (2019). Direct human health risks of increased atmospheric carbon dioxide. Nature Sustainability, 2(8), 691-701.

Karjalainen, S. (2007). Gender differences in thermal comfort and use of thermostats in everyday thermal environments. Building and Environment, 42(4), 1594-1603.

Karjalainen, S. (2012). Thermal comfort and gender: A literature review. Indoor Air, 22(2), 96-109.

Lan, L., Lian, Z., Liu, W., \& Liu, Y. (2008). Investigation of gender difference in thermal comfort for Chinese people. European Journal of Applied Physiology, 102(4), 471-480.

Leonard, B. (1998). Electric Power Annual 1995 Volume II, DIANE Publishing Company, DOE/EIA: 0348(95)/2.
Panfil, M. (2014), "Resiliency+: demand response can help prevent blackouts in the northeast", blog, from http:// blogs.edf.org/energyexchange/2014/06/30/resiliencydemand-response-can-help-prevent-blackouts-in-the-north east/ retrieved on 05/01/2021

Sustainable Energy Authority of Ireland. "Energy contracting." 2020, from https://www.seai.ie/business-and-public-sector/business-grants-and-supports/energy-contracting/. Accessed on 05/01/2021

Van Hoof, J. (2008). Forty years of Fanger's model of thermal comfort: Comfort for all? Indoor Air, 18(3), 182-201.

Wisconsin Department of Health Services (2019), from https:// www.dhs. wisconsin.gov/chemical/carbondioxide.htm, accessed on 05/01/2021

Xu, PR., Yin, C., Brown \& Kim D.E. (2009). "Demand shifting with thermal mass in large commercial buildings in a California hot climate zone.", California Energy Commission, PIER Energy-Related Environmental Research Program, https://doi.org/10.2172/988082

Zhang, F., De Dear, R., \& Candido, C. (2016). Thermal comfort during temperature cycles induced by direct load control strategies of peak electricity demand management. Building and Environment, 103, 9-20.

Zhang, H., Arens, E., \& Pasut, W. (2011). Air temperature thresholds for indoor comfort and perceived air quality. Building Research \& Information, 39(2), 134-144.

Publisher's note Springer Nature remains neutral with regard to jurisdictional claims in published maps and institutional affiliations. 